\title{
CANINE SIZE VARIABILITY IN EXTINCT HOMININ TAXA WITH SPECIAL EMPHASIS IN THE HOMO HABILIS: PALAEOBIOLOGICAL AND TAXONOMICAL IMPLICATIONS
}

\author{
Juan M. JIMÉNEZ-ARENAS ${ }^{1,2}$ \\ ${ }^{1}$ Departamento de Prehistoria y Arqueología, Universidad de Granada, Facultad \\ de Filosofía y Letras. Campus de Cartuja s/n, 18071 Granada, Spain. \\ ${ }^{2}$ Instituto Universitario de la Paz y los Conflictos-IPAZ, Universidad de Granada. \\ Edificio de Documentación Científica. C/ Rector López Argüeta, s/n, 18071 \\ Granada, Spain; jumajia@ugr.es
}

Jiménez-Arenas, J. M. 2012. Canine size variability in extinct hominin taxa with special emphasis in the Homo habilis: Palaeobiological and taxonomical implications. [Variabilidad en el tamaño de los caninos de los homininos extintos con especial énfasis en Homo habilis: Implicaciones paleobiológicas y taxonómicas]. Revista Española de Paleontología, 27 (1), 1-14. ISSN 0213-6937.

\begin{abstract}
The canines of hominins are quite different in both size and shape compared to those of their closest extant relatives (chimpanzees and gorillas). On the other hand, it has been argued that canine size and sexual size dimorphism is related to socio-sexual behaviour, but there is only limited evidence as to whether these aspects are informative regarding the behaviour of extinct hominins. This issue is complicated by the difficulty to sex the upper canines of fossil hominins and uncertain taxonomic attribution. In order to make palaeobiological inferences on the behaviour of these taxa, in this paper the variability in upper canine area is evaluated in extinct hominins, on the basis of the coefficient of variation, by using re-sampling procedures. Particular emphasis is put on Homo habilis s.l., by evaluating variability in several groupings of upper canines attributable to this taxon. The results indicate that, in most instances, extinct hominins cannot be significantly distinguished from chimpanzees and modern humans regarding canine area variability. It is therefore concluded that canine area is not a good variable to infer behavioural aspects of extinct hominins. In addition, when the sets of $H$. habilis s.l. including KNM-ER 1590 (a 1.85 My older H. rudolfensis representative described as a juvenile male) showed a variability superior to that of anatomically modern humans, which suggests those sets including such individual may represent more than one taxon.
\end{abstract}

Keywords: Sexual size dimorphism, bootstrapping, KNM-ER 1590.

\section{RESUMEN}

Los caninos de los homininos muestran diferencias tanto en tamaño como en forma respecto a los de sus parientes más cercanos (chimpancés y gorilas). Por otra parte, se ha propuesto que el tamaño de los caninos y el dimorfismo sexual de éste se relaciona con el comportamiento socio-sexual, no obstante, hay pocas evidencias de si estos aspectos son informativos respecto al comportamiento de los homininos extintos. Esta cuestión se ve complicada por la dificultad de asignar un sexo a los caninos superiores de los homininos fósiles y también de la incertidumbre taxonómica asociada. Con la intención de establecer inferencias paleobiológicas sobre el comportamiento de estos taxones, en este artículo se evalúa la variabilidad del área de los caninos superiores de los homininos usando como aproximación a la misma el coeficiente de variación mediante el uso de procedimientos de remuestreo. Particular énfasis se ha puesto en Homo habilis s.l. evaluando la variabilidad en diferentes agrupaciones de caninos superiores atribuibles a este taxón. Los resultados indican que, en la mayoría de los casos, la variabilidad de los caninos superiores de los homininos extintos no difiere significativamente de los chimpancés y de los humanos modernos. Por tanto, se concluye que el área de los caninos no es una buena variable para inferir aspectos del comportamiento de los homininos extintos. Además, los grupos de H. habilis s.l. que incluyen a KNM-ER 1590 (un representante de H. rudolfensis descrito como un macho juvenil y con una cronología de 1,85 Ma) muestran una variabilidad superior a la de los humanos anatómicamente modernos lo cual sugiere que tales grupos pueden contener especímenes pertenecientes a más de un taxón.

Palabras clave: Dimorfismo sexual en el tamaño, bootstrapping, KNM-ER 1590. 


\section{INTRODUCTION}

One of the most outstanding characteristics of hominins is the presence of incisiform canines (White et al., 1994; Senut et al., 2001; Brunet et al., 2002). In addition, the degree of canine sexual dimorphism is lesser in hominins than in great apes (Leutenegger \& Shell, 1987; Kelley, 1995; Greenfield, 1998; Plavcan \& van Schaik, 1997; Plavcan, 2000; Wood \& Richmond, 2000). On the other hand, since Darwin (1871), it is a well-known fact that canine size and canine sexual dimorphism have a social component. Therefore, morphological changes in the canines including decreasing dimensions and size dimorphism have led to palaeobiological and taxonomical inferences about extinct hominin taxa. Both size and sexual dimorphism in non-human primates upper canines have been considered, together with body mass, the best proxies to agonistic and socio-sexual behaviour (Plavcan \& van Schaik, 1992, 1997; Plavcan, 1993, 1998, 2000; Plavcan et al., 1995).

Based on living species, several authors have attempted to recreate the behaviour of extinct hominin taxa (Leutenegger \& Shell, 1987; Plavcan \& van Schaik, 1997; Plavcan, 2000; Lee, 2005; Suwa et al., 2009). Particularly, Suwa et al. (2009) have proposed a substantial change in the behaviour of Ardipithecus ramidus based on the morphological changes and reduced size of the canines in this species that compromises the living chimpanzee as a behavioural model for the ancestral hominid condition. Nonetheless, several authors have noted that canine size alone is inadequate for making inferences in fossil hominins (Leutenegger \& Shell, 1987; Plavcan \& van Schaik, 1997; Plavcan, 2000; Lee, 2005; Jiménez-Arenas, 2009). Furthermore, the reduced size of the anterior dentition in addition to canine evolution towards a more incisiform morphology both suggest that changes in diet also took place (Darwin, 1859, 1971; Jolly, 1970; Greenfield, 1992a). Specifically, it has been suggested that hominins seem to have adopted a more granivorous diet (Jolly, 1970; Greenfield, 1992a). On the other hand, Darwin also suggested that canine reduction in hominins occurred gradually in parallel with the progressive use of clubs, stones, and other weapons that enabled these individuals to tackle their enemies (Darwin, 1871).

The preceding discussion raises several taxonomic issues. The changes in the size and shape of canines, the loss of the canine honing complex, and the projection of the canines are all considered crucial factors to define the most ancient taxa of hominins (White et al., 1994; Senut et al., 2001; Brunet et al., 2002). On the other hand, upper canine differences are conspicuous among males and females of the great apes. By contrast, hominin upper canines are relatively small with a low level of sexual size dimorphism. These features cause a potential overlapping in the canine size of various extinct hominin taxa, which limits the use of canine morphometrics to discern about taxonomy in this specific taxon but not between fossil hominins and some extant great apes. Moreover, size overlap across males and females within an extinct hominin taxon poses an additional challenge to sex discrimination.

In the present study we used the upper canine area of extinct hominin taxa from the Plio-Pleistocene for which sufficient data were available in the literature $(\mathrm{N} \geq 5)$. We subsequently compared upper canine size variability of fossil hominins with that of three modern reference species: Gorilla gorilla, Pan troglogytes, and Homo sapiens. Therefore, the aims of this paper are (1) to evaluate if it is possible to make palaeobiological inferences of sociosexual behaviour of several hominin extinct taxa based on levels of canine size sexual dimorphism and (2) to test if the individuals classified as $H$. habilis s.l. constitute a single taxon or, on the contrary, make up two taxa.

\section{MATERIALS AND METHODS}

The area of the upper canine (C'A) was our variable of interest. Following Plavcan (1990), mesiodistal (C'MD) and buccolingual (C'BL) lengths were measured in the occlusal plane at the base of the maxillary canines, being MD the maximum mesiodistal length and BL perpendicular to the MD axis. The area was calculated as the product of both lengths in $\mathrm{mm}^{2}$. The author measured 191 individuals of living species (see species distribution in Table 1). Gorillas were represented by equal numbers of males and females of the subspecies Gorilla gorilla gorilla. The group of chimpanzees (Pan troglodytes) included specimens from two of the known subspecies, P. t. schweinfurthii, and P. t. troglodytes. In order to add variability to our modern humans specimens, samples were extracted from three different sources: a Spanish medieval necropolis (La Torrecilla, Arenas del Rey, Granada, Spain), a dental clinic (Rincón de la Victoria, Málaga, Spain), and a collection of Pleistocene modern humans from Europe and the Middle East published by Genet-Varcin (1979) and Vandermeersch (1981) (Table 1). The extinct hominin taxa used in this study were Ardipithecus ramidus ( $\mathrm{N}=$ 9), Australopithecus anamensis ( $\mathrm{N}=3)$, Australopithecus afarensis $(\mathrm{N}=11)$, Australopithecus africanus $(\mathrm{N}=13)$, Australopithecus robustus $(\mathrm{N}=12)$ and Homo habilis s.l. $(\mathrm{N}=8)$ (Table 2 and Figs 1, 2).

We used the coefficient of variation (CV) to estimate within-taxon variability. The $\mathrm{CV}$ is a normalized measure of dispersion of a probability distribution and is defined as the ratio of the standard deviation and the average:

$$
\mathrm{CV}=\mathrm{SD} / \bar{x}
$$


Table 1. Origin, sex and number of observations (N) of living species used in the present study.

Legend; 0 : male; + : female; u.k.: unknown; LAFUGR: Physical Anthropology Laboratory of the University of Granada (Spain); IAUZ: Institute of Anthropology of the University of Zurich (Switzerland); RMAC: Royal Museum of Central Africa (Tervuren, Belgium); (a) as measured by the author of the present study; (b) De Lumley (1973); ${ }^{(c)}$ Genet-Varcin (1979), (d) Vandermeersch (1981).

\begin{tabular}{|c|c|c|c|}
\hline Species & Origin & Sex & $\mathrm{N}$ \\
\hline \multirow{6}{*}{ H. sapiens } & \multirow{3}{*}{ LAFUGR $^{(a)}$} & $\hat{\sigma}$ & 32 \\
\hline & & $q$ & 24 \\
\hline & & u.k. & 3 \\
\hline & \multirow{2}{*}{$\begin{array}{c}\text { Clínica Navajas- } \\
\text { Del Valle }^{(\mathrm{a})}\end{array}$} & $\hat{0}$ & 19 \\
\hline & & q & 14 \\
\hline & Pleistocene $^{(\mathrm{b}, \mathrm{c}, \mathrm{d})}$ & u.k. & 11 \\
\hline \multicolumn{3}{|c|}{ Total H. sapiens } & 103 \\
\hline \multirow{2}{*}{$\begin{array}{l}\text { P. troglodytes } \\
\text { troglodytes }\end{array}$} & \multirow{2}{*}{ IAUZ/RMAC(a) } & 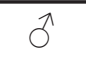 & 17 \\
\hline & & q & 21 \\
\hline \multirow{2}{*}{$\begin{array}{c}P . t . \\
\text { schweinfurthii }\end{array}$} & \multirow{2}{*}{$\mathrm{RMAC}^{(\mathrm{a})}$} & $\pi$ & 11 \\
\hline & & q & 9 \\
\hline \multicolumn{3}{|c|}{ Total P. troglodytes } & 58 \\
\hline \multirow{2}{*}{$\begin{array}{l}\text { G. gorilla } \\
\text { gorilla }\end{array}$} & \multirow{2}{*}{ IAUZ ${ }^{(a)}$} & 0 & 15 \\
\hline & & q & 15 \\
\hline \multicolumn{3}{|c|}{ Total G. gorilla } & 30 \\
\hline
\end{tabular}

Table 2. Descriptive statistics of each of the taxa used in the present study. Measurements in $\mathrm{mm}^{2}$.

Legend; N: sample size; $\bar{x}$ : mean; SD: standard deviation; $\mathrm{CV}$ : coefficient of variation; ${ }^{(*)}$ Habilines 1 ; (e) Suwa et al. (2009); (f) Ward et al. (2001); (g) Kimbel et al. (2004); (h) Wood (1991); ${ }^{(\mathrm{i})}$ Moggi-Cecchi et al. (2006); ${ }^{(j)}$ Kimbel et al. (1997); ${ }^{(\mathrm{k})}$ Blumenschine et al. (2003); (1) Rightmire et al. (2006).

\begin{tabular}{cccccc}
\hline Taxon & $\mathrm{N}$ & $\bar{X}$ & $\mathrm{SD}$ & $\mathrm{CV}$ & Source \\
\hline H. sapiens & 103 & 63.81 & 10.26 & 16.07 & $(\mathrm{a}, \mathrm{b}, \mathrm{c}, \mathrm{d})$ \\
P. troglodytes & 58 & 134.97 & 41.50 & 30.75 & (a) \\
G. gorilla & 30 & 265.07 & 101.13 & 38.15 & (a) \\
Ar. ramidus & 9 & 105.91 & 12.63 & 11.93 & $(\mathrm{e})$ \\
Au. anamensis & 3 & 115.60 & 13.37 & 11.57 & $(\mathrm{f})$ \\
Au. afarensis & 11 & 106.10 & 14.04 & 13.24 & $(\mathrm{~g})$ \\
Au. africanus & 13 & 102.71 & 18.66 & 18.17 & $(\mathrm{~h}, \mathrm{i})$ \\
Au. robustus & 12 & 82.13 & 11.89 & 14.48 & $(\mathrm{~h})$ \\
H. habilis (s.l. $)^{(*)}$ & 8 & 97.27 & 20.94 & 21.53 & $(\mathrm{~h}, \mathrm{j}, \mathrm{k}, \mathrm{l})$ \\
\hline
\end{tabular}

This measurement has long been used to evaluate size dimorphism and taxonomy when sex is unknown in a sample (e.g., Simpson et al., 1960; Kramer et al., 1995; Lorenzo et al., 1998; Lockwood, 1999). These approaches start from the next premise: if a fossil sample exceeds the variation of a set of living species, specifically those that present a high level of sexual size dimorphism (e.g., gorillas), the possibility of that sample encompasses more than one taxon arises. This fact is particularly relevant for the 'habilines' topic because the taxonomic diversity of the early members of Homo is a central issue of palaeoanthropology. Thus the scientific community is divided between those who suggest a single species, Homo habilis (e.g., Howell, 1978; Jiménez-Arenas et al., 2011), as opposed to those who advocate for two separate species, $H$. habilis and H. rudolfensis (e.g., Alexeev, 1986; Wood \& Collard, 1999).

In order to include in the analyses as many consistent groups of fossils as possible, a series of 'Habilines' (TH) sets were created (Table 3). Each set is based on taxonomical and/or geographical criteria, which would allow us to identify the discordant specimens, if any, within the original grouping composed of $H$. habilis s.l. TH 1 encompasses $H$. habilis s.l. including the Georgian representative D2732 from Dmanisi because it has been claimed the affinities between the Caucasian population and the earliest representatives of the genus Homo (Lordkipanidze et al., 2007; Jiménez-Arenas et al., 2011). TH 2 embraces the $H$. habilis s.l. from Olduvai Gorge $(\mathrm{OH})$ at Tanzania and East Lake Turkana (ER) at Kenya. TH 3 sets the H. habilis s.s. individuals. TH 4 groups the $H$. habilis s.s. individuals from $\mathrm{OH}$ and ER. TH 5 includes the preceding group excepting OH 65 who resembles as KNM-ER 1470 (H. rudolfensis holotype) as $\mathrm{OH} 7$ ( $H$. habilis s.s. holotype) (see Blumenschine et al., 2003 for a further discussion). TH 6 comprehends the $H$. habilis s.l. fossils from OH, ER and Dmanisi. TH 7 is composed by the H. habilis s.s. and Dmanisi representatives. TH 8 encompasses $H$. habilis s.s. from OH, ER and Dmanisi. Finally, TH 9 includes $H$. habilis s.s. representatives excepting $\mathrm{OH} 65$.

Subsequently, we resampled from the extant species original samples to study the variability of the various fossil hominin taxa. The null hypothesis is that groups of fossil hominins would fall within the range of variation of the three modern species used for comparison. These living species were chosen because they are the fossil hominins closest relatives and comprise three different mating systems: harem (gorillas), multimale-multifemale (chimpanzees) and pair bond (modern humans). On the other hand, the goal is to determine the probability of sampling a set of $\mathrm{N}$ individuals from an extant hominin species whose coefficient of variation exhibit size differences in the canine greater than those present in different samples of $\mathrm{N}$ individuals of several groupings of fossil hominins. 


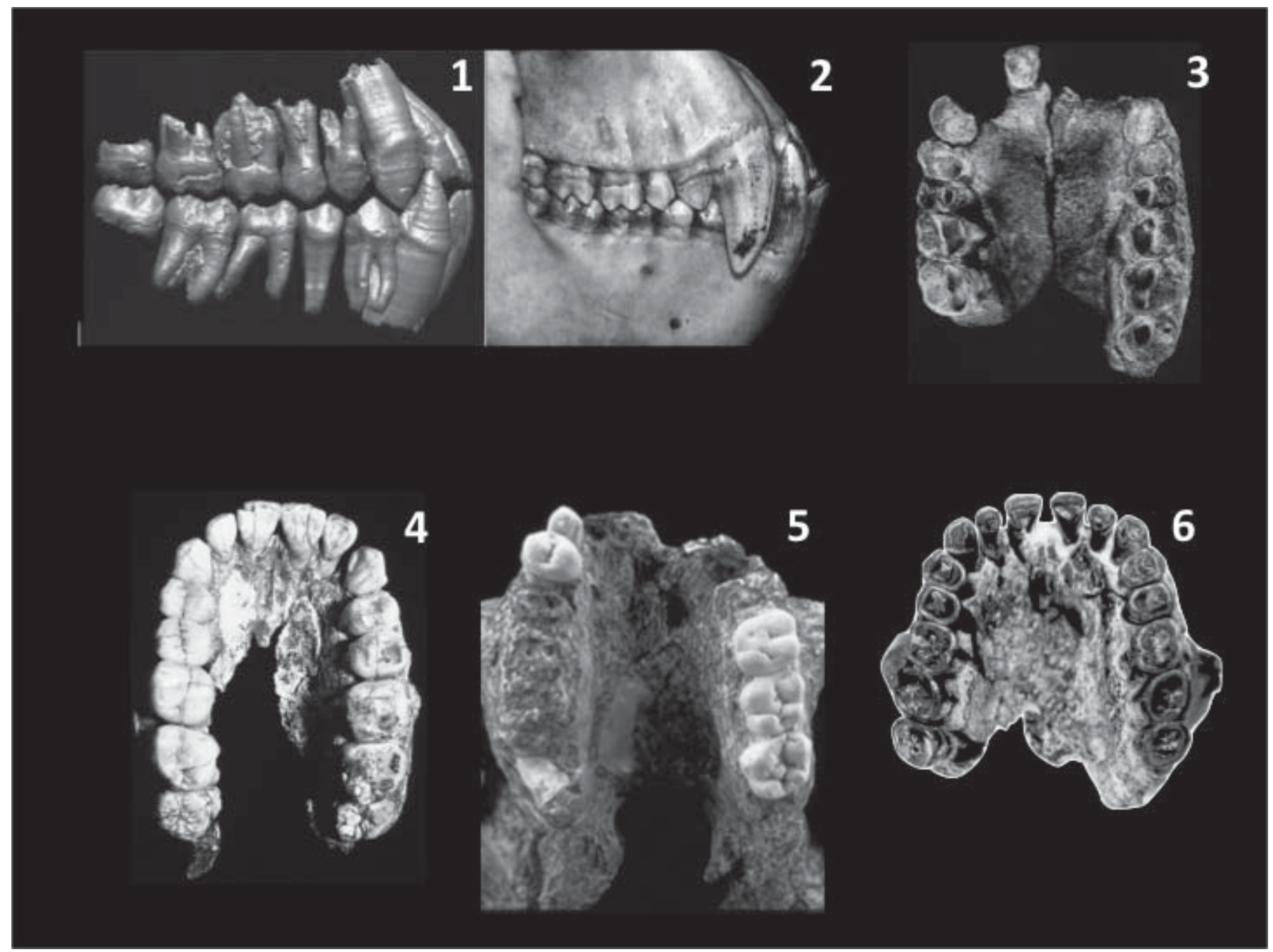

Figure 1. Dentition of selected hominins. 1: Ar. ramidus, ARA-VP-6/500 (superior and inferior teeth, buccal view, right). 2: P. troglodytes, male (skull, lateral view, right). 3: Au. anamenis, KP-29283, (maxilla, superior view). 4: Au. africanus, Sts 62, (maxilla, superior view). 5: Au. robustus, SK 48 (maxilla, superior view). 6: H. habilis, OH 65 (maxilla, superior view).

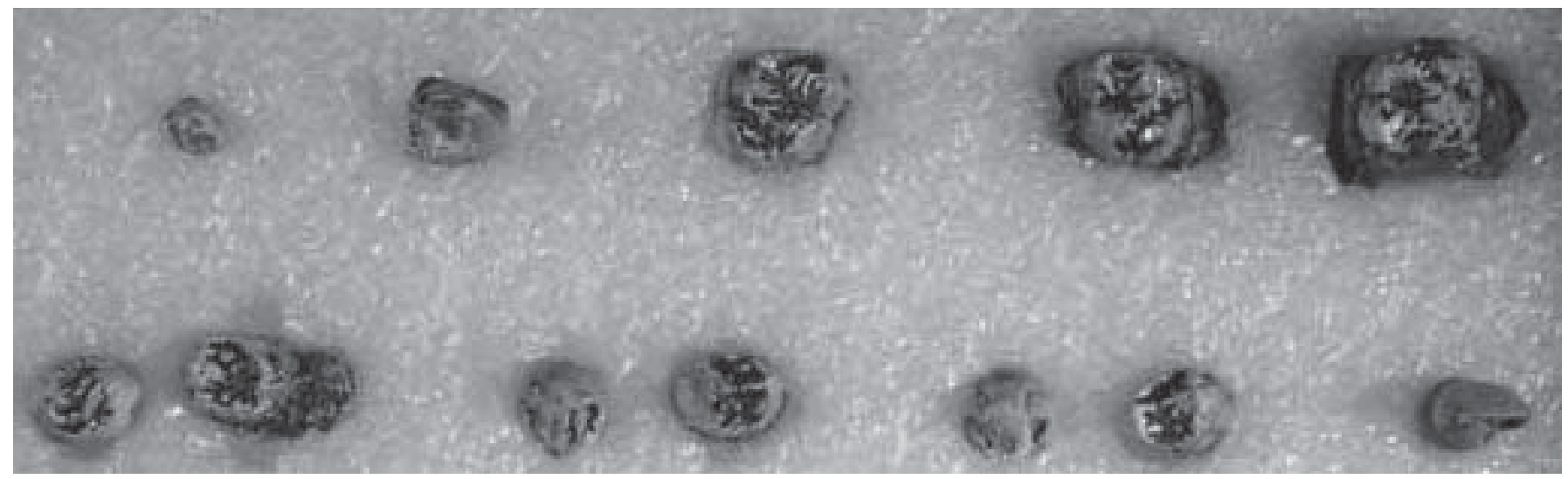

Figure 2. H. rudolfensis, KNM-ER 1590 (isolated superior and inferior teeth, occlusal view). 
Table 3. Composition of the different groups of Habilines (TH) (see Appendix for further information).

TH 1. A.L. 666-1; KNM-ER 1590, KNM-ER 1813, KNM-ER 1805; OH 16, OH 39, OH 65; D 2732

\begin{tabular}{|c|c|}
\hline $\mathrm{N}$ & 8 \\
\hline$X$ & 97.27 \\
\hline SD & 20.94 \\
\hline $\mathrm{CV}$ & 21.53 \\
\hline \multicolumn{2}{|c|}{$\begin{array}{l}\text { TH 2. KNM-ER 1590, KNM-ER 1813, KNM-ER } \\
\text { 1805; OH 16, OH 39, OH } 65\end{array}$} \\
\hline $\mathrm{N}$ & 6 \\
\hline$X$ & 94.77 \\
\hline SD & 24.13 \\
\hline $\mathrm{CV}$ & 25.47 \\
\hline \multicolumn{2}{|c|}{$\begin{array}{l}\text { TH 3. A.L. 666-1, KNM-ER 1813, KNM-ER 1805; } \\
\text { OH 16, OH 39, OH } 65\end{array}$} \\
\hline $\mathrm{N}$ & 6 \\
\hline $\bar{X}$ & 88.35 \\
\hline SD & 10.48 \\
\hline $\mathrm{CV}$ & 11.86 \\
\hline
\end{tabular}

TH 4. KNM-ER 1813, KNM-ER 1805;

$\mathrm{OH} 16, \mathrm{OH} 39, \mathrm{OH} 65$

\begin{tabular}{lr}
\hline $\mathrm{N}$ & 5 \\
$\bar{X}$ & 85.42 \\
$\mathrm{SD}$ & 8.54 \\
$\mathrm{CV}$ & 10.00 \\
\hline
\end{tabular}

TH 5. KNM-ER 1813, KNM-ER 1805;

OH 16, OH 39

\begin{tabular}{lr}
\hline $\mathrm{N}$ & 4 \\
$\mathrm{SD}$ & 83.50 \\
$\mathrm{CV}$ & 8.52 \\
\hline $\mathrm{TH} 6 . \mathrm{KNM}-\mathrm{ER} \mathrm{1590,} \mathrm{KNM-ER} \mathrm{1813,} \mathrm{KNM-ER}$ & \\
$1805 ; \mathrm{OH} 16, \mathrm{OH} 39 ; \mathrm{OH} 65 ;$ D2732 \\
\hline $\mathrm{N}$ & 7 \\
$\bar{X}$ & 96.45 \\
$\mathrm{SD}$ & 22.48 \\
$\mathrm{CV}$ & 23.31 \\
\hline
\end{tabular}

TH 7. A.L. 666-1, KNM-ER 1813, KNM-ER 1805; $\mathrm{OH} 16, \mathrm{OH} 39, \mathrm{OH} 65 ; \mathrm{D} 2732$

\begin{tabular}{lr}
\hline $\mathrm{N}$ & 7 \\
$\bar{X}$ & 90.95 \\
$\mathrm{SD}$ & 11.79 \\
$\mathrm{CV}$ & 12.96 \\
\hline $\mathrm{TH}$ 8. KNM-ER 1813, KNM-ER 1805; \\
$\mathrm{OH} 16, \mathrm{OH} 39, \mathrm{OH} 65 ;$ D2732 \\
\hline $\mathrm{N}$ & 68.94 \\
$\bar{X}$ & 11.52 \\
$\mathrm{SD}$ & 12.96 \\
\hline
\end{tabular}

TH 9. KNM-ER 1813, KNM-ER 1805;

$\mathrm{OH} 16, \mathrm{OH} 39 ; \mathrm{D} 2732$

\begin{tabular}{lr}
\hline $\mathrm{N}$ & 5 \\
$\bar{X}$ & 88.11 \\
$\mathrm{SD}$ & 12.68 \\
$\mathrm{CV}$ & 14.39 \\
\hline
\end{tabular}

Sampling techniques have been used successfully to establish the extent of sexual dimorphism in fossil hominin populations (Arsuaga et al., 1997; Lorenzo et al., 1998), and to discriminate variability due to sexual dimorphism from variability due to different taxa in a set of fossils (e.g., Kramer, 1993; Terhune et al., 2007; Baab, 2008).

Owed to the fact that estimates of the CV are dependent on sample size, and can be therefore highly biased given the very small sample sizes available for fossil hominin fossils (Cope \& Lacy, 1992; Foote, 1993). We used a bootstrapping procedure (range 5-13) to generate a number of samples $(\mathrm{N}=5,000)$ that would guarantee adequate statistical power (Lorenzo et al., 2005). We used one- and two-tailed Student $t$ tests to assess whether extinct hominin taxa or Habilines groupings significantly differ from living species regarding the degree of variability. All statistical analyses were conducted with JMP version 9 (SAS Campus Drive, Cary, NC).

\section{RESULTS}

Table 3 presents a set of descriptive statistics. As a result of its prominent sexual dimorphism, the modern species with greater variability was $G$. gorilla. The $H$. sapiens, on the other hand, had the smallest canine size and the lowest variability. The canine size of $P$. troglodytes ranged in an intermediate position between G. gorilla and $H$. sapiens. If we exclude $H$. habilis s.l. from the analysis, the extinct taxon with highest variability was Australopithecus africanus, followed by $\mathrm{Au}$. robustus, Au. afarensis, Ar. ramidus, and Au. anamensis. Meanwhile, H. habilis s.l. showed the highest variability. Nevertheless, when KNMER 1590 was excluded from the analysis, $H$. habilis variability ranked between those of $A u$. afarensis and Ar. ramidus (Table 3). This finding led us to evaluate further the behaviour of different groups of $H$. habilis s.l.

Canine size means were significantly different across modern species (Table 4), while extinct taxa showed no significant differences. Extinct taxa and anatomically modern humans were also indistinguishable. The only extinct taxon that was statistically different from chimpanzees was $A u$. robustus. Finally, the canine size of gorillas differed significantly from all extinct taxa.

When we compared extinct taxa with extant species we cannot reject the null hypothesis because all of those fell in the range of variation of the three modern taxa including in this study (Tables 3, 5, 6; Figs 3, 4). The only exception was those Habilines groupings when the individual KNM-ER 1590 was included (TH 1, TH 2, TH 6) because surpassed the upper limit of the confidence interval of the coefficient of variation modern humans (Tables 3, 5, 6; Fig. 4). Finally, none of the fossil hominins, again excluding KNM-ER 1590, reached the lower limit of the confidence interval of the coefficient of variation of gorillas (Table 7). 
Table 4. Student $t$ test comparing the canine size means of various taxa (see references in Tables 1 and 2). ns: non significant.

\begin{tabular}{|c|c|c|c|c|c|c|c|c|c|}
\hline & G. gorilla & P. troglodytes & Ar. ramidus & Au. anamensis & Au. afarensis & Au. africanus & Au. robustus & H. habilis (s.1.) & H. sapiens \\
\hline G. gorilla & - & $<.05$ & $<.05$ & $<.05$ & $<.05$ & $<.05$ & $<.05$ & $<.05$ & $<.05$ \\
\hline P. troglodytes & & - & ns & ns & ns & ns & $<.05$ & ns & $<.05$ \\
\hline Ar. ramidus & & & - & ns & ns & ns & ns & ns & ns \\
\hline Аu. anamensis & & & & - & ns & ns & ns & ns & ns \\
\hline Au. afarensis & & & & & - & ns & ns & ns & ns \\
\hline Au. africanus & & & & & & - & ns & ns & ns \\
\hline Au. robustus & & & & & & & - & ns & ns \\
\hline H. habilis (s.1.) & & & & & & & & - & ns \\
\hline
\end{tabular}

\section{DISCUSSION}

The coefficient of variation is highly sensitive to sexual size dimorphism and it does not require individuals to be sexed (Simpson et al., 1960), which is critical when sex cannot be determined as is often the case in analyses based on the fossil record. Sex determination based on the fossil record is particularly difficult when the remains available demonstrate low sexual size dimorphism, as it is the case of canines of fossil hominins. According to our results, the greatest variability and, in turn, the greatest sexual size dimorphism was found among gorillas, while the lowest was found among modern humans. These findings are coherent with those reported in the literature (Leutenegger \& Kelly, 1977; Leutenegger, 1982; Leutenegger \& Shell, 1987; Plavcan, 1990, 1993, 2000; Plavcan \& van Schaik, 1992, 1997). Although taxonomic and palaeobiological aspects are strongly linked, in the next two subsections we discuss both individually.

\section{PALAEOBIOLOGICAL ASPECTS}

Most studies analyzing canine size of extinct hominins have focused on the social behaviur in this clade, because a wide range of primates does not use canine teeth for food processing (e.g., Plavcan, 2000). Only a group of New World monkeys, the Pithecines, are an exception to this rule because use canines for processing nuts with hard shells. For all other anthropoid primates, canines play an important social role in intrasexual competition and mating (Kay et al., 1988; Plavcan, 1990, 1993, 2000; Greenfield, 1992a, b; Plavcan \& van Schaik, 1992, 1997; Plavcan et al., 1995; Jiménez-Arenas, 2009). The question remains if such a social function could be extrapolated to extinct hominins. According to the results of this study, the variability of a large group of extinct hominins taxa and groups fell within the range of variability of chimpanzees and anatomically modern humans. However, when KNM-ER 1590 was included in the analysis, hominins' variability increased significantly to a level comparable with the variability observed among gorillas.
Furthermore, none of the Habilines groups excluding KNM-ER 1590 reached the lower limit of gorilla's confidence interval, which would be consistent with both the reduced canine size and the canine sexual size dimorphism of extinct hominins and anatomically modern humans. These results would imply that gorillas could be inadequate for comparisons with the Homo genus. In addition, Rensch's rule predicts that sexual dimorphism in body size tends to increase as body size increases in a group of related species (Rensch, 1959). Gorillas present a significant difference in body mass concerning the Homo genus, particularly $H$. habilis s.l. As a palaeobiological inference, the mating system of 'Habilines' not containing KNM-ER 1590 would be compatible with the mating system observed among chimpanzees and humans. As a consequence, we can propose two different options. The first one, the Habilines groups containing KNM-ER 1590 display a mating system similar to that of gorillas. The second one, gorillas could be considered as an inadequate neontological referent to infer this kind of palaeobiological aspects in fossil hominins. For the reasons exposed above, we opt for the first one.

Nevertheless, these earlier studies have compared the variability of extinct taxa and living species regardless the sample size. As indicated above, the CV estimated for a particular sample is highly dependent on the sample size (Cope \& Lacy, 1992; Foote, 1993). For example, it would not be possible to compare a fossil sample composed of 5 individuals with a sample of any extant species composed of fifty. Thus, Leutenegger \& Shell (1987) concluded that (1) Au. afarensis and bonobos have a similar level of dimorphism, (2) Au. boisei is slightly less dimorphic than $A u$. afarensis, (3) Au. robustus is more dimorphic than Hylobates lar, and (4) Au. africanus dimorphism ranges between that of $H$. lar and modern humans. These authors also pointed out the existence of dissociation in the size dimorphism of body and canine sizes. Finally, Leutenegger \& Shell (1987) concluded that australopithecines were unlikely to have used their canines as weapons during intrasexual competitions. These findings have been partially 
Table 5. Descriptive statistics of random re-sampling with replacement of the coefficient of variation of the upper canine area $(\mathrm{N}=5,000)$. Measurements in $\mathrm{mm}^{2} . \mathrm{N}$ (samples): number of specimens in each re-sampling; $\bar{x}$ : mean; SD: standard deviation; u.1.: 95\% one-tailed confidence interval upper limit; CI: 95\% two-tailed confidence interval.

\begin{tabular}{|c|c|c|c|c|c|}
\hline species & $\mathrm{N}$ & $\bar{x}$ & SD & u.1. & CI \\
\hline \multirow{10}{*}{ G. gorilla } & 13 & 37.65 & 5.33 & 44.64 & $28.73-46.56$ \\
\hline & 12 & 37.58 & 5.28 & 44.51 & $28.74-46.41$ \\
\hline & 11 & 37.56 & 5.25 & 44.45 & $28.78-46.34$ \\
\hline & 10 & 37.66 & 5.28 & 44.59 & $28.82-46.50$ \\
\hline & 9 & 37.65 & 5.71 & 44.15 & $28.10-47.20$ \\
\hline & 8 & 37.55 & 6.13 & 45.60 & $27.30-47.81$ \\
\hline & 7 & 37.22 & 7.14 & 46.59 & $22.28-49.15$ \\
\hline & 6 & 37.16 & 8.35 & 48.13 & $23.19-51.14$ \\
\hline & 5 & 36.69 & 9.99 & 49.81 & $19.99-53.40$ \\
\hline & 4 & 36.07 & 12.53 & 52.53 & $15.12-57.03$ \\
\hline \multirow{10}{*}{ P. troglodytes } & 13 & 29.76 & 6.07 & 37.73 & $19.61-39.91$ \\
\hline & 12 & 30.07 & 6.06 & 38.03 & $19.94-40.21$ \\
\hline & 11 & 29.80 & 6.03 & 37.72 & $19.71-39.89$ \\
\hline & 10 & 29.95 & 6.18 & 38.06 & $19.62-40.28$ \\
\hline & 9 & 29.62 & 6.46 & 38.10 & $18.81-40.42$ \\
\hline & 8 & 29.46 & 6.95 & 38.58 & $17.83-41.08$ \\
\hline & 7 & 29.53 & 7.57 & 39.48 & $16.87-42.20$ \\
\hline & 6 & 29.12 & 8.16 & 39.84 & $15.47-42.77$ \\
\hline & 5 & 28.72 & 9.46 & 41.14 & $12.90-44.53$ \\
\hline & 4 & 27.81 & 10.72 & 41.89 & $9.88-45.74$ \\
\hline \multirow{10}{*}{ H. sapiens } & 13 & 14.07 & 4.36 & 19.80 & $6.78-21.37$ \\
\hline & 12 & 13.90 & 4.35 & 19.65 & $6.63-21.17$ \\
\hline & 11 & 14.09 & 4.42 & 19.89 & $6.70-21.48$ \\
\hline & 10 & 14.03 & 4.42 & 19.84 & $6.64-21.42$ \\
\hline & 9 & 13.90 & 4.59 & 19.93 & $6.22-21.58$ \\
\hline & 8 & 13.87 & 4.81 & 20.18 & $5.83-21.91$ \\
\hline & 7 & 13.77 & 5.10 & 20.47 & $5.25-22.30$ \\
\hline & 6 & 13.53 & 5.44 & 20.68 & $4.43-22.63$ \\
\hline & 5 & 13.28 & 5.85 & 20.96 & $3.49-23.06$ \\
\hline & 4 & 13.04 & 6.45 & 21.51 & $2.25-23.83$ \\
\hline
\end{tabular}

replicated by Plavcan \& van Schaik (1997). According to these authors, canine length and width of australopithecines overlap considerably rendering these variables uninformative to discern between males and females. On the other hand, the height of the crown, in spite of being relatively well correlated with the mating system of anthropoids, it is a poor predictor when used with fossil hominins and particularly in the Homo genus. In summary, canines and body mass may be considered as two distinct proxies of sexual dimorphism. Therefore assuming that they are different estimates of the same thing is misleading. On the other hand, canine area may not be a piece of information from which aspects of primate behaviour could be inferred. Lee (2005) emphasizes the disparity of sexual size dimorphism levels obtained through different variables and the ensuing interpretative challenges. Therefore, this study adds to the preexisting literature suggesting that canine occlusal area has a low resolution and it should not be used to support palaeobiological inferences about fossil hominins by the means of the use of a large amount of extant species resamples with the same number of observations than those of extinct hominin taxa.

Table 6. Agreement probabilities for the null hypothesis (coefficient of variation of fossil hominines does not surpass the variability range of modern species). Legend: Ggor: G. gorilla; Ptrog: P. troglodytes; Hsap: $H$. sapiens; ns: non significant.

\begin{tabular}{|c|c|c|c|}
\hline taxa/grouping & Ggor & Ptrog & Hsap \\
\hline Ar. ramidus & ns & ns & ns \\
\hline Au. afarensis & ns & ns & ns \\
\hline Au. africanus & ns & ns & ns \\
\hline Au. robustus & ns & ns & ns \\
\hline TH 1 & ns & ns & $<.05$ \\
\hline TH 2 & ns & ns & $<.05$ \\
\hline TH 3 & ns & ns & ns \\
\hline TH 4 & ns & ns & ns \\
\hline TH 5 & ns & ns & ns \\
\hline TH 6 & ns & ns & $<.05$ \\
\hline TH 7 & ns & ns & ns \\
\hline TH 8 & ns & ns & ns \\
\hline TH 9 & ns & ns & ns \\
\hline
\end{tabular}

$A u$. robustus provides an outstanding example to illustrate the ambiguity of results depending on the chosen variable. This australopithecine has been described as a taxon with a very high level of sexual dimorphism in body size (Lockwood et al., 2007). Moreover, it has been suggested that $A u$. robustus had a mating system similar to that of gorillas with a single male monopolizing a small group of females (Lockwood et al., 2007). Meanwhile, young males would wander beyond the limits of the territory occupied by the alpha male and his harem, becoming easy prey for predators. There is evidence to suggest that terrestrial primates, especially those who inhabit the plains and become separated from youth groups are exposed to a 

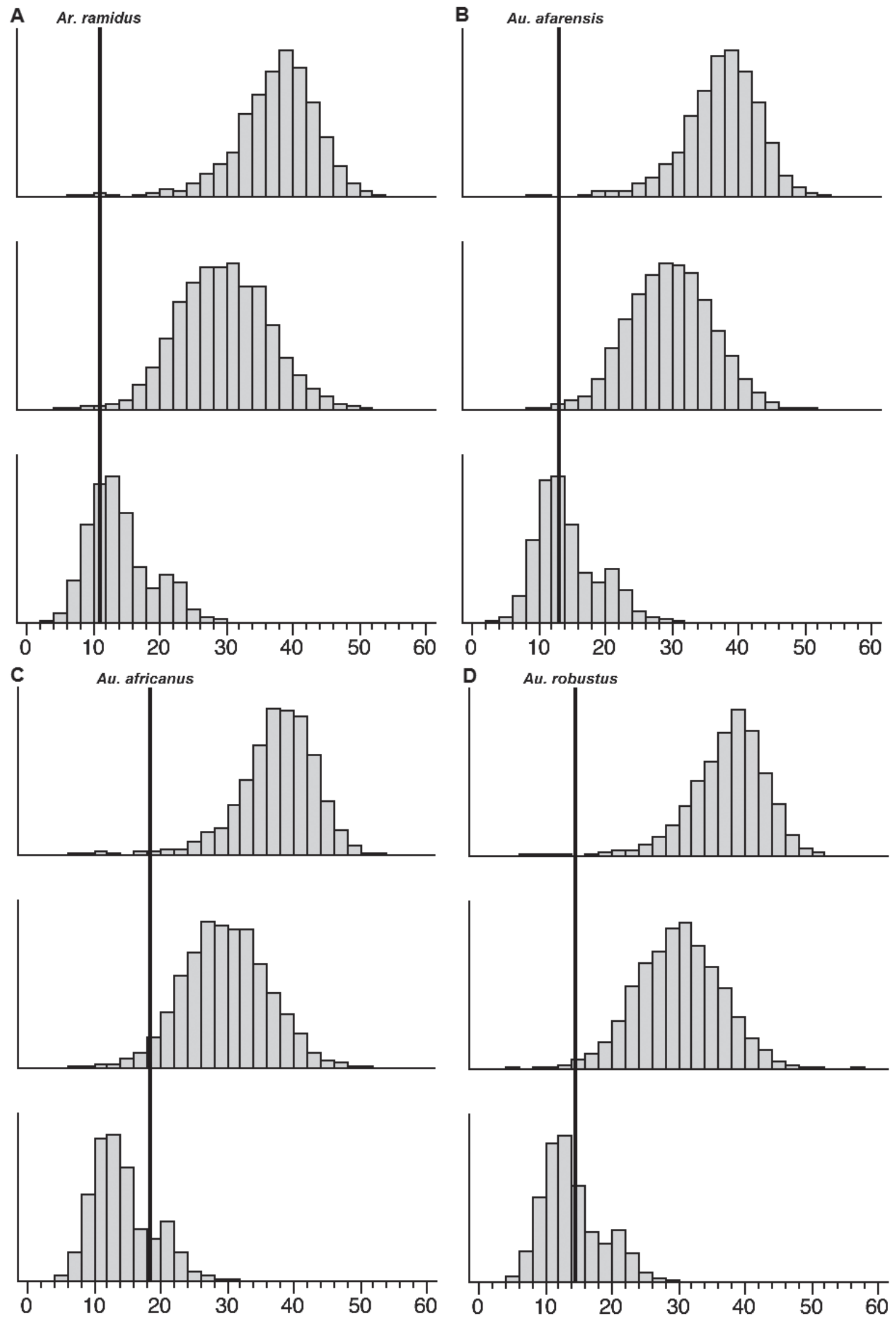

Figure 3. Bar graph showing the distribution of coefficients of variation of canine area of modern species. Vertical lines A, B, C, and $\mathrm{D}$ indicate the variation coefficient value for Ar. ramidus, Au. afarensis, Au. africanus, and Au. robustus. All histograms are adjusted to the same size. 

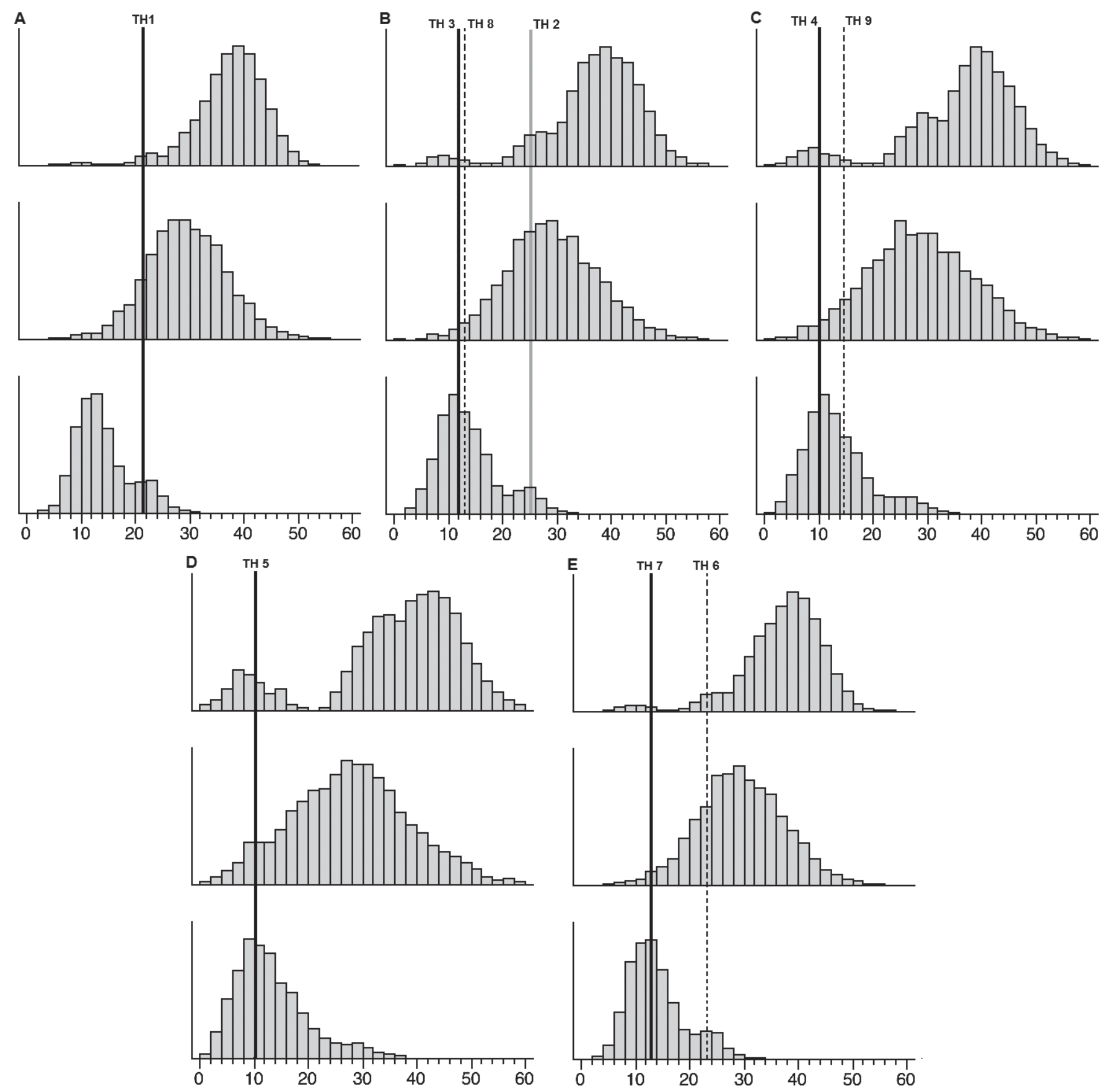

Figure 4. Bar graph showing the distribution of the coefficient of variation of the canine area of modern species. Vertical lines indicate the variation coefficient value for the different groups of the Habilines (TH). A: TH 1. B: solid black line, TH 3; solid grey line, TH 2; stripped black line, TH 8. C: solid black line, TH 4; stripped black line, TH 9. D: TH 5. E: solid black line, TH 7; stripped black line, TH 6 . All histograms are adjusted to the same size.

high risk of predation (Stelzner \& Strier, 1981; Cheney \& Wrangham, 1987; Boesch, 1991). Nevertheless, we show in this study that $\mathrm{Au}$. robustus displays the lowest canine occlusal area variability of all extinct hominin taxa. For these reasons, any interpretations about behaviour change across species (Ar. ramidus) based only on canine size sexual dimorphism (Suwa et al., 2009) should be taken with caution until additional variables, specifically body mass, are examined.
Finally, the evidence does not support a decreasing trend of the occlusal surface of the canines for an hominization time span of over 2.5 million years starting with the first appearance of Ar. ramidus ( $4.4 \mathrm{My})$ and expanding until the emergence of $H$. habilis ( 2.4 My) and $A u$. robustus ( 1.8 My). Differences across extinct taxa are not statistically significant. Moreover, we could not establish a decreasing trend of sexual dimorphism in canine size overtime. The extinct taxon with greater variability 
Table 7. Agreement probabilities for the null hypothesis (coefficient of variation of fossil hominines does not surpass the lower limit of the variability range of $G$. gorilla). Legend; see Table 6.

\begin{tabular}{lc}
\hline taxa/grouping & Ggor \\
\hline Ar. ramidus & $<.05$ \\
Au. afarensis & $<.05$ \\
Au. africanus & $<.05$ \\
Au. robustus & $<.05$ \\
TH 1 & $\mathrm{~ns}$ \\
TH 2 & $\mathrm{~ns}$ \\
TH 3 & $<.05$ \\
TH 4 & $<.05$ \\
TH 5 & $<.05$ \\
TH 6 & $\mathrm{~ns}$ \\
TH 7 & $<.05$ \\
TH 8 & $<.05$ \\
TH 9 & $<.05$ \\
\hline
\end{tabular}

was $A u$. africanus. On the other hand, Ar. ramidus, a taxon that preceded $\mathrm{Au}$. africanus, showed a lower level of variability. Nonetheless, our results show that the reduction of canine size may have not followed a linear process as Darwin (1871) hypothesized. This conclusion finds support in the lack of significant differences across taxa expanding over a 2.5-million-year period. According to the evidence available, we should discard a causal link between canine size reduction and nature-culture changes in the resolution of conflicts, as Darwin suggested. Tools with the potential to be used as weapons do not appear in the archaeological record until a much later stage in the evolution of hominins ( $400 \mathrm{ky})$. Specifically, the loss of the penetration capability of the canines pre-dates the Schöningen spears (Thieme, 1997) in at least 6 Million years.

\section{TAXONOMIC INFERENCES}

Canine size has also been used as evidence in the taxonomy of fossil hominins. Johanson \& White (1979) found a statistically significant difference between the average canine buccolingual width of $A u$. afarensis and $A u$. africanus. Although these authors indicated that the number of individuals included in the analyses could explain, at least in part, the reported results. Our results were not consistent with those of Johanson \& White (1979) because we have been able to expand the number of observations by incorporating new materials from specimens of Au. afarensis (Kimbel et al., 2004) and Au. africanus (Moggi-Cecchi et al., 2006), which caused the results to vary substantially. The average canine area did not differ significantly between $A u$. afarensis and Au. africanus $\left(A u\right.$. afarensis $=106.1 \mathrm{~mm}^{2}$ and $A u$. africanus $=102.7 \mathrm{~mm}^{2}$; Table 3 ). The lack of differences in canine area was also found for all other extinct hominins. Therefore, canine size may be considered a low-resolution variable to support taxonomic inferences in extinct hominins.

Moreover, canine occlusal surface does not discriminate between fossil hominins and the genus Pan. This seems to be mainly due to the effect of the canine size of females -when analyses are restricted to males, fossil hominin taxa are statistically significant (Table 8). Therefore, in order to differentiate the canines of hominin fossils from those of extant Panini, we should turn to morphological traits and the tooth wear pattern. A merely morphometric analysis seem to be insufficient to discriminate effectively between both taxonomic groups.

Table 8. Results of the Student $t$ test comparing the mean canine size of chimpanzees and extinct taxa. Legend; see Table 6 .

\begin{tabular}{|c|c|c|c|c|c|}
\hline & $\begin{array}{c}\text { Ar. } \\
\text { ramidus }\end{array}$ & $\begin{array}{c}A u . \\
\text { afarensis }\end{array}$ & $\begin{array}{c}A u . \\
\text { africanus }\end{array}$ & $\begin{array}{c}A u . \\
\text { robustus }\end{array}$ & $\begin{array}{l}\text { H. habilis } \\
\text { (s.l.) }\end{array}$ \\
\hline P. troglodytes ${ }^{\lambda}$ & $<.05$ & $<.05$ & $<.05$ & $<.05$ & $<.05$ \\
\hline P. troglodytes ${ }_{+}$ & ns & $\mathrm{ns}$ & $\mathrm{ns}$ & $<.05$ & $\mathrm{~ns}$ \\
\hline
\end{tabular}

However, the variability of canine occlusal surfaces shed some light on the actual number of taxa under the informal label of Habilines. There is an intense debate over the taxa that compose $H$. habilis, whether one (e.g., Howell, 1978; Jiménez-Arenas et al., 2011), or two $-H$. habilis, H. rudolfensis (e.g., Alexeev, 1986; Wood \& Collard 1999).

It is important to note that all taxa pertaining to 'archaic hominins' (Wood \& Lonergan, 2008) fell within the variability range of anatomically modern humans, gorillas and chimpanzees. On the contrary, Habilines including KNM-ER 1590 exceeded the variability of anatomically modern humans. Moreover, regarding the KNM-ER 1590 Habilines groupings, the coefficients of variation were higher than those of 'archaic hominins' reported in this study (Ar. ramidus, Au. anamensis, Au. afarensis, $A u$. africanus and $A u$. robustus). KNM-ER 1590 upper canine area is certainly large $\left(141.5 \mathrm{~mm}^{2}\right)$, with a value almost double of KNM-ER 1813, a H. habilis s.s. representative $\left(71.4 \mathrm{~mm}^{2}\right)$. It should be noted that the size of KNM-ER 1590 permanent dentition is bigger than the dentition of any other member of the genus Homo (Pérez-Claros et al., 2006). For this reason, the addition of KNR-ER 1590 in groupings of fossil hominins results in an outstanding increase of the coefficient of variation, suggesting that such groupings could include more than one taxon.

Therefore, it could be the case that KNM-ER 1590 is an unusual case which would suggest three possibilities:

1. KNM-ER 1590 is an outlier and, as such, it should be removed from all analyses. Specifically, as a conse- 
quence of the small sample size of our analysis (e.g., Habilines $\mathrm{n} \leq 8$ ), including KNM-ER 1590 could generate an artefactual portrayal of the real variability of the $H$. habilis s.l. canine sizes.

2. We shall consider two taxonomical alternatives for KNM-ER 1590 based on the dimensions of the canine occlusal surface. First, the $H$. habilis sensu lato may be divided in two taxa: $H$. habilis and $H$. rudolfensis. Second, KNM-ER 1590 may not be a representative of the genus Homo. From a morphometric standpoint, KNM-ER 1590 extraordinary canine size seems closer to BOU-VP-12/130, a representative of $A u$. garhi with a dentition similar in size to KNM-ER 1590 (Asfaw et al., 1999).

3. We could speculate about a temporal interspecific trend toward smaller individuals. According to a recent chronostratigraphic survey conducted in Koobi Fora, the level from which KNM-ER 1470, and all of the so-called $H$. rudolfensis specimens were extracted, dates back to a period older $(\sim 250 \mathrm{ky})$ to those stratigraphic levels contained H. habilis s.s. (Gathogo \& Brown, 2006). In order to support this hypothesis, we have incorporated modern humans from different chronologies (range $20 \mathrm{ky}$ ). The results suggest that the canine size decreased overtime (La Torrecilla was 21\% smaller than Pleistocene humans). Nevertheless, such reduction is not so dramatic as that showed by Habilines.

An additional consideration suggesting that KNM-ER 1590 may be an unusual specimen comes from the observed variability of the groupings of Habilines including the only individual from Dmanisi (Georgia) that we were able to measure. Canine size variability in these groups fell within the variability range of anatomically modern humans. In addition, the canine area of such groups did not depart from the canine area variability observed among fossil hominins taxa.

\section{CONCLUSIONS}

The conclusions that follow are based on the results obtained in the present study.

1. Gorillas seems inadequate species for comparative analyses with fossil hominin taxa due to (1) the high variability of the canine occlusal size of those extant species, and (2) the conspicuous differences in canine size when compared with taxa/groupings of extinct hominins.

2. Excepting those groupings including KNM-ER 1590, extinct hominins do not differ significantly from chimpanzees and modern humans regarding canine area variability. It is therefore drawn that canine area is not a good variable to infer socio-sexual aspects of extinct hominins.

3. The sets of Habilines including KNM-ER 1590 showed a variability superior to that of anatomically modern humans. The variability of these sets departed greatly from the variability of 'archaic hominins' included in the present study, which suggests that sets including KNMER 1590 may represent more than one taxon $(H$. habilis s.s. and $H$. rudolfensis). The additional taxon would likely be $H$. rudolfensis, although $A u$. garhi may also be a good candidate due to its morphometric similarity with KNM-ER 1590.

4. KNM-ER 1590 could be considered and outlier and ought to be removed from the present analysis due to the small sample size of our study.

\section{ACKNOWLEDGEMENTS}

The author would like to thank the following persons who facilitated access to the materials preserved at their respective institutions: Vim var Neer (Royal Museum of Central Africa, Tervuren, Belgium), Marcia Ponce de León (Anthropologisches Institut, University of Zurich, Switzerland), José Manuel Navajas (Navajas-Del Valle Othontological Clinic, Rincón de la Victoria, Spain), and Miguel Botella (Laboratory of Physical Anthropology, University of Granada, Spain). This study has been supported by the projects CGL2010-18124 and HAR2008-04577 funded by the Spanish Ministry of Science and Innovation and by the research group HUM-607 of the Andalusian Government (Junta de Andalucía). B. Martínez-Navarro and the anonymous reviewer provided insightful comments on earlier versions of this manuscript. The author was under a return contract funded by a program of the University of Granada (Spain) when this study was being conducted.

\section{REFERENCES}

Alexeev, P.V. 1986. The Origin of the Human Race. Progress Publishers, Moscow.

Arsuaga, J.L., Carretero, J.M., Lorenzo, C., Gracia, A., Martínez, I., Bermúdez de Castro, J.M. \& Carbonell, E. 1997. Size variation in Middle Pleistocene humans. Science, 277, 1086-1088.

Asfaw, B., White, T., Lovejoy, O., Latimer, B., Simpson, S. \& Suwa, G. 1999. Australopithecus garhi: A new species of early hominid from Ethiopia. Science, 284, 629-635.

Baab, K.L. 2008. The taxonomic implications of cranial shape variation in Homo erectus. Journal of Human Evolution, 54, 827-847.

Blumenschine, R.J., Peters, C.R., Masao, F.T., Clarke, R.J., Deino, A.L., Hay, R.L., Swisher, C.C., Stanistreet, I.G., Ashley, G.M., McHenry, L.J., Sikes, N.E., Van der Merwe, N.J., Tactikos, J.C., Deocampo, D.M., Njau, J.K. \& Ebert, J.I. 2003. Late Pliocene Homo and hominid land use from Western Olduvai Gorge, Tanzania. Science, 299, 1217-1221.

Boesch, C. 1991. The effects of leopard predation on grouping patterns in forest chimpanzees. Behaviour, 117, 220-241. 
Brunet, M., Guy, F., Pilbeam, D., Mackaye, H.T., Likius, A., Ahounta, D., Beauvilain, A., Blondel, C., Bocherens, H., Boisserie, J.-R., De Bonis, L., Coppens, Y., Dejax, J., Denys, C., Duringer, P., Eisenmann, V., Fanone, G., Fronty, P., Geraads, D., Lehmann, T., Lihoreau, F., Louchart, A., Mahamat, A., Merceron, F., Mouchelin, G., Otero, O., Pelaez-Campomanes, P., Ponce de León, M., Rage, J.-C., Sapanet, M., Sudre, J., Tassy, P., Valentin, X., Vignaud, P., Virlot, L., Zazzo, A. \& Zollikofer, C. 2002. A new hominid from the Upper Miocene of Chad, Central Africa. Nature, 418, 145-151.

Cheney, D.L. \& Wrangham, R.W. 1987. Predation. In: Primates Societies (Eds. B.B. Smuts, D.L. Cheney, R.M. Seyfarth, R.W. Wrangham \& T.T. Struhsaker). University of Chicago Press, Chicago, 227-239.

Cope, D.A. \& Lacy, M.G. 1992. Falsification of a single species hypothesis using the coefficient of variation: A simulation approach. American Journal of Physical Anthropology, 89, 359-378.

Darwin, C. 1859. On the Origin of Species by Means of Natural Selection. John Murray, London.

Darwin, C. 1871. The Descent of Man and Selection in Relation to Sex. John Murray, London.

De Lumley, M.-A. 1973. Anténéandertaliens et Néandertaliens du bassin méditerranéen occidental européen. Études Quaternaries, 2, 1-626.

Foote, M. 1993. Human cranial variability: A methodological comment. American Journal of Physical Anthropology, 90, 377-379.

Gathogo, P.N. \& Brown, F.H. 2006. Revised stratigraphy of Area 123, Koobi Fora, Kenya, and new age estimates of its fossil mammals, including hominins. Journal of Human Evolution, 51, 471-479.

Genet-Varcin, E. 1979. Les Hommes Fossiles. Societé Nouvelle des Éditions Boubée, Paris.

Greenfield, L.O. 1992a. Origin of the human canine: A new solution to an old enigma. American Journal of Physical Anthropology, 35, 153-185.

Greenfield, L.O. 1992b. Relative canine size, behavior and diet in male ceboids. Journal of Human Evolution, 23, 469-480.

Greenfield, L.O. 1998. Canine tip wear in male and female anthropoids. American Journal of Physical Anthropology, 107, 87-96.

Howell, F.C. 1978. Hominidae. In: Evolution of African mammals (Eds. V.J. Maglio \& H.B.S. Cooke). Harvard University Press, Cambridge, 154-258.

Jiménez-Arenas, J.M. 2009. Una evaluación de la función social de los caninos y sus consecuencias en evolución humana. In: Comunicaciones de las XXV Jornadas de la Sociedad Española de Paleontología "Darwin, la Teoría de la Evolución y la Paleontología” y simposios de los proyectos 493, 499 y 506 (Eds. P. Palmqvist \& J.A. Pérez-Claros). Universidad de Málaga, Málaga, Abstract Book, 91-94.

Jiménez-Arenas, J.M., Palmqvist, P. \& Pérez-Claros J.A. 2011. A probabilistic approach to the craniometric varia- bility of the genus Homo and inferences on the taxonomic affinities of the first population dispersing out of Africa. Quaternary International, 243, 219-230.

Johanson, D. \& White, T. 1979. A systematic assessment of early African hominids. Science, 203, 321-330.

Jolly, C.J. 1970. The seed-eaters: A new model of hominid differentiation based on a baboon analogy. Man, 5, 5-26.

Kay, R.F., Plavcan, J.M., Glander, K.E. \& Wright, P.C. 1988. Sexual selection and canine dimorphism in new world monkeys. American Journal of Physical Anthropology, 77, 385-397.

Kelley, J. 1995. Sex determination in Miocene catarrhine primates. American Journal of Physical Anthropology, 96, 391-417.

Kimbel, W.H., Johanson, D.C. \& Rak, Y. 1997. Systematic assessment of a maxilla of Homo from Hadar, Ethiopia. American Journal of Physical Anthropology, 103, 235-262.

Kimbel, W.H., Rak, Y. \& Johanson D.C. 2004. The Skull of Australopithecus afarensis. Oxford University Press, New York.

Kramer, A.1993. Human taxonomic diversity in the Pleistocene: does Homo erectus represent multiple hominid species? American Journal of Physical Anthropology, 91, 161-171.

Kramer, A., Donnelly, S.M., Kidder, J.H., Ousley, S.D. \& Olah, S.M. 1995. Craniometric variation in large-bodied hominoids: testing the single-species hypothesis for Homo habilis. Journal of Human Evolution, 29, 443-462.

Lee, S.H. 2005. Patterns of size sexual dimorphism in Australopithecus afarensis: Another look. HOMO - Journal of Comparative Human Biology, 56, 219-232.

Leutenegger, W. 1982. Scaling of sexual dimorphism in body weight and canine size in primates. Folia Primatologica, 37, 163-176.

Leutenegger, W. \& Kelly, J. 1977. Relationship of sexual dimorphism in canine size and body size to social, behavioral, and ecological correlates in anthropoid primates. Primates, 18, 117-136.

Leutenegger, W. \& Shell, B. 1987. Variability and sexual dimorphism in canine size of Australopithecus and extant hominoids. Journal of Human Evolution, 16, 359-367.

Lockwood, C.A. 1999. Sexual dimorphism in the face of Australopithecus africanus. American Journal of Physical Anthropology, 108, 97-127.

Lockwood, C.A., Menter, C.G., Moggi-Cecchi, J. \& Keyser, A.W. 2007. Extended male growth in a fossil hominin species. Science, 318, 1443-1446.

Lordkipanidze, D., Jashashvili, T., Vekua, A., Ponce de León, M.S., Zollikofer, C.P., Rightmire, G.P., Pontzer, H., Ferring, R., Oms, O., Tappen, M., Bukhsianidze, M., Agustí, J., Kahlke, R., Kiladze, G., Martínez-Navarro, B, Mouskhelishvili, A., Nioradze, M. \& Rook, L. 2007. Postcranial evidence from early Homo from Dmanisi, Georgia. Nature, 449, 305-310.

Lorenzo, C., Carretero, J.M., Arsuaga, J.L., Gracia, A. \& Martínez, I. 1998. Intrapopulational body size variation and cranial capacity variation in middle pleistocene humans: 
The Sima de los Huesos sample (Sierra de Atapuerca, Spain). American Journal of Physical Anthropology, 106, 19-33.

Lorenzo, C., Martínez, I., Arsuaga, J.L. \& Gracia, A. 2005. Bootstrap method and the analysis of cranial capacity variation in the Dmanisi fossils and Homo ergaster. American Journal of Physical Anthropology, 126, 145.

Moggi-Cecchi, J., Grine, F.E., \& Tobias, P.V. 2006. Early hominid dental remains from Members 4 and 5 of the Sterkfontein Formation (1966-1996 excavations): Catalogue, individual associations, morphological descriptions and initial metrical analysis. Journal of Human Evolution, 50, 239-328.

Pérez-Claros, J.A., Jiménez Arenas, J.M. \& Palmqvist, P. 2006. Análisis de las relaciones entre la fosa cigomática, el área de la dentición postcanina y el volumen endocraneal en homininos: Inferencias paleoecológicas y evolutivas. In: XXII Jornadas de la Sociedad Española de Paleontología y Simposios de los Proyectos PICG 493, 499 y 467. (Ed. E. Fernández Martínez). Universidad de León, León, Abstract Book, 69-72.

Plavcan, J.M. 1990. Sexual Dimorphism in the Dentition of Extant Anthropoid Primates. Duke University, Durham.

Plavcan, J.M. 1993. Canine size and shape in male Anthropoid Primates. American Journal of Physical Anthropology, 92, 201-216.

Plavcan, J.M. 1998. Correlated response, competition, and female canine size in primates. American Journal of Physical Anthropology, 107, 401-416.

Plavcan, J.M. 2000. Inferring social behavior from sexual dimorphism in the fossil record. Journal of Human Evolution, 39, 327-344.

Plavcan, J.M. \& Van Schaik, C.P. 1992. Intrasexual competition and canine dimorphism in Anthropoid Primates. American Journal of Physical Anthropology, 87, 461477.

Plavcan, J.M. \& Van Schaik, C.P. 1997. Interpreting hominid behavior on the basis of sexual dimorphism. Journal of Human Evolution, 32, 345-374.

Plavcan, J.M., Van Schaik, C.P. \& Kappeler, P.M. 1995. Competition, coalitions and canine size in primates. Journal of Human Evolution, 28, 245-276.
Rensch, B. 1959. Evolution Above the Species Level. Columbia University Press, New York.

Rightmire, G.P., Lordkipanidze, D. \& Vekua, A. 2006. Anatomical descriptions, comparative studies and evolutionary significance of the hominin skulls from Dmanisi, Republic of Georgia. Journal of Human Evolution, 50, 115-141.

Senut. B., Pickford, M., Gommery, D., Mein, P., Cheboi, K. \& Coppens, Y. 2001. First hominid from the Miocene (Lukeino Formation, Kenya) Premier hominidé du Miocène (formation de Lukeino, Kenya). Comptes Rendus de l'Academie des Sciences - Series IIA - Earth and Planetary Science, 332, 137-144.

Simpson, G.G., Roe, A. \& Lewontin, R.C. 1960. Quantitative Zoology, Revised Edition. Harcourt, Brace and World, New York

Stelzner, J. \& Strier, K. 1981. Hyena predation on an adult male baboon. Mammalia, 45, 259-260.

Suwa, G., Kono, R.T., Simpson, S.W., Asfaw, B., Lovejoy, C.O. \& White, T.D. 2009. Paleobiological implications of the Ardipithecus ramidus dentition. Science, 326, 64-99.

Terhune, C.E., Kimbel, W.H. \& Lockwood, C.A. 2007. Variation and diversity in Homo erectus: a 3D geometric morphometric analysis of the temporal bone. Journal of Human Evolution, 53, 41-60.

Thieme, H. 1997. Lower Palaeolithic hunting spears from Germany. Nature, 385, 807-810.

Vandermeersch, B. 1981. Les Hommes Fossiles de Qafzeh (Israël). Université Pierre et Marie Curie, Paris.

Walker, A. \& Leakey, R.E.F. 1978. The hominids of East Turkana. Scientific American, 239, 54-66.

Ward, C.V., Leakey, M.G. \& Walker, A. 2001. Morphology of Australopithecus anamensis from Kanapoi and Allia Bay, Kenya. Journal of Human Evolution, 41, 255-368.

White, T.D., Suwa, G. \& Asfaw, B. 1994. Australopithecus ramidus, a new species of early hominid from Aramis, Ethiopia. Nature, 371, 306-312.

Wood, B. 1991. Koobi Fora. Research Project 4. Hominid cranial remains. Clarendon Press, Oxford.

Wood, B. \& Collard, M. 1999. The human genus. Science, 284, 65-71.

Wood, B. \& Lonergan, N. 2008. The hominin fossil record: taxa, grades and clades. Journal of Anatomy, 212, 354-376.

Manuscrito recibido: 24 de enero, 2012 Manuscrito aceptado: 30 de abril, 2012 


\section{Appendix.}

Relevant information about the $H$. habilis s.l. representatives used in this study.

\begin{tabular}{|c|c|c|c|c|c|}
\hline Individual & Species & Locality & $\begin{array}{l}\text { Date } \\
\text { (My) }\end{array}$ & $\begin{array}{c}\text { Sex } \\
\text { (assigned) }\end{array}$ & Preserved parts \\
\hline A.L. 666-1 & H. habilis & Hadar (Ethiopia) & 2.3 & Unknown & Maxilla \\
\hline D 2732 & H. georgicus & Dmanisi (Georgia) & 1.8 & Unknown & Isolated canine \\
\hline KNM-ER 1590 & H. rudolfensis & Koobi Fora (Kenya) & 1.9 & Male & Partial cranium and teeth \\
\hline KNM-ER 1805 & H. habilis & Koobi Fora (Kenya) & 1.7 & Unknown & Partial cranium and teeth \\
\hline KNM-ER 1813 & H. habilis & Koobi Fora (Kenya) & 1.65 & Female & Cranium \\
\hline $\mathrm{OH} 16$ & H. habilis & $\begin{array}{l}\text { Olduvai Hominid Site } \\
\text { (Tanzania) }\end{array}$ & 1.7 & Male & Partial cranium and teeth \\
\hline OH 39 & H. habilis & $\begin{array}{l}\text { Olduvai Hominid Site } \\
\text { (Tanzania) }\end{array}$ & - & Unknown & Teeth \\
\hline $\mathrm{OH} 65$ & H. habilis & $\begin{array}{l}\text { Olduvai Hominid Site } \\
\text { (Tanzania) }\end{array}$ & 1.8 & Female & Maxilla \\
\hline
\end{tabular}

